\title{
APROXIMAÇÃO ENTRE REALIDADE E "FICÇÃO MATEMÁTICA" DE ISABELLE STENGERS, COM O USO DO GEOGEBRA
}

\author{
APPROXIMATION BETWEEN REALITY AND "MATHEMATICAL \\ FICTION" OF ISABELLE STENGERS, WITH THE USE OF GEOGEBRA
}

Nilton Carlos Costa ${ }^{1}$

ORCID iD: $\underline{\text { 0000-0002-5350-2501 }}$

Railce da Silva de Azevedo ${ }^{2}$

ORCID iD: 0000-0001-7879-462X

Alcides Castro Amorim Neto ${ }^{3}$

ORCID iD: 0000-0002-5463-4047

\begin{abstract}
RESUMO
O artigo tem como temática a aproximação entre realidade e "ficção matemática" de Isabelle Stengers, com o uso do GeoGebra. A pesquisa justifica-se pela importância da discussão acerca dos dilemas e percalços oriundos ao ensino de matemática, levando em consideração a teoria do conhecimento defendida por Isabelle Stengers (1949). Para tanto, utilizou-se da pesquisa bibliográfica a partir das ideias de autores como Brasil (1998), D'Ambrosio (1986), Ausubel (1983), dentre outros. O objetivo geral dá-se em determinar de que forma softwares como o GeoGebra pode ser uma ferramenta de aproximação entre a realidade e a "ficção" no Ensino da Matemática. A proposta investigativa será apresentada em três seções, sendo a primeira referente a alguns conceitos vinculados à teoria de Isabelle Stengers, posteriormente abre-se espaço para uma breve discussão sobre algumas contribuições da autora para o ensino de ciências, levando em consideração o conceito de ficção matemática e em seguida a aproximação da ficção matemática com a realidade usando o GeoGebra. Em suma, percebe-se que as contribuições da teoria de Isabelle Stengers ainda permanecem válidas e muito presentes no contexto do ensino atual.
\end{abstract}

Palavras-chave: Ficção. Realidade. Ensino de Ciências. Ensino de Matemática. GeoGebra.

\begin{abstract}
The article has as its theme the approximation between reality and "mathematical fiction" of Isabelle Stengers, with the use of GeoGebra. The research is justified by the importance of the discussion about the dilemmas and mishaps arising from the teaching of mathematics, taking into account the theory of knowledge defended by Isabelle Stengers (1949). In order to do so,

1 Graduado em Licenciatura em Matemática pela Universidade do Estado do Amazonas (UEA), Manaus, Amazonas, Brasil. Mestrando em Educação e Ensino de Ciências na Amazônia pela Universidade do Estado do Amazonas (UEA), Manaus, Amazonas, Brasil. Endereço para correspondência: Rua Santa Ana Nery, número 61, Ouro verde, Manaus, Amazonas, Brasil, CEP: 69082-425. E-mail: nilton_carlos2009@ hotmail.com.

${ }^{2}$ Graduada em Licenciatura em Pedagogia pela Universidade Federal do Amazonas (UFAM), Manaus, Amazonas, Brasil. Mestranda em Educação e Ensino de Ciências na Amazônia pela Universidade do Estado do Amazonas (UEA), Manaus, Amazonas, Brasil. Endereço para correspondência: Rua Otávio Cabral, número 27, Petrópolis, Manaus, Amazonas, Brasil, CEP: 69067-370. E-mail: railcedasilvadeazevedo@ hotmail.com.

${ }^{3}$ Doutor em Clima e Ambiente pelo Instituto Nacional de Pesquisas da Amazônia (IMPA). Professor do Programa de Pós-graduação em Educação e Ensino de Ciências na Amazônia da Universidade do Estado do Amazonas (UEA), Manaus, Amazonas, Brasil. Endereço para correspondência: Rua Bem-te-vi, casa 01, Conjunto Parque das garças, bairro cidade nova, Manais, Amazonas, Brasil. CEP: 69000-000. E-mail: dooham2007@ gmail.com.
\end{abstract}


we used bibliographical research based on the ideas of authors such as Brazil (1998), D'Ambrosio (1986), Ausubel (1983), among others. The research proposal will be presented in three sections, the first one referring to some concepts linked to the theory of Isabelle Stengers, later opens space for a brief discussion about some contributions of the author to science teaching, taking into account the concept of fiction mathematics and then the approximation of mathematical fiction with reality using GeoGebra. In sum, it is perceived that the contributions of Isadelle Stengers's theory still remain valid and very present in the context of the current teaching.

Keywords: Fiction. Reality. Science Teaching. Mathematics Teaching. GeoGebra.

\section{INTRODUÇÃO}

Os estudos atuais apontam que se faz necessária uma aproximação entre a realidade do que se ensina em matemática e o uso na experiência de vida do aluno. $\mathrm{O}$ estudo do Todos pela Educação, feito com base nos dados do Saeb de 2007 a 2017, mostra que a maioria dos jovens que se formam no Ensino Médio tem grandes dificuldades em português e em matemática. O nível de aprendizado é baixo e os avanços para acelerar esse cenário são lentos. Ainda segundo o movimento Todos pela Educação, de cada dez alunos que se formam, sete têm defasagens em português $(70,9 \%)$. No caso da matemática, a situação é ainda pior: mais de $90 \%$ (90,9\%) saem do Ensino Médio sem o aprendizado adequado (EDUCACADOR BRASIL ESCOLA, 2020).

Nesse sentido, apresentaremos as ideias de Isabelle Stengers, nascida em 1949, é uma filosofa e historiadora belga, e filha do historiador Jean Stengers. Formou-se em química na Universidade Livre de Bruxelas. É autora de inúmeros trabalhos, entre eles um que se destacou, intitulado A Nova Aliança (1991), escrito em conjunto com o ganhador do Prêmio Nobel de Química de 1977, Ilya Prigogine, sobre a teoria do caos, propõe uma nova visão da ciência, da percepção dos fenômenos organizacionais e da relação do cientista com a natureza, sob o paradigma da complexidade. Stengers é graduada em Química, doutora em Filosofia e leciona na Universidade Livre de Bruxelas. Como professora, entende os desafios de sala de aula e aponta para a modernização das ciências também no contexto escolar.

O objetivo geral dá-se em determinar de que forma softwares como o GeoGebra podem ser uma ferramenta de aproximação entre a realidade e a "ficção" no Ensino da Matemática. Quanto à metodologia, utilizaremos da pesquisa bibliográfica, pois buscamos alinhar diversos autores de livros, artigos, dissertações, entrevistas e outros, que mostrem as possíveis aproximações que o uso de softwares como o GeoGebra proporciona no Ensino da matemática.

Dessa forma, este artigo está baseado nas indagações sobre o ensino de Matemática como uma atividade em constante construção, e mesmo com inúmeras pesquisas a respeito, 
percebe-se que a temática não está esgotada. Para subsidiar tal estudo, questiona-se: quais aproximações precisam ser feitas no ensino de matemática entre o fictício matemático e a realidade? O software GeoGebra pode ser uma ferramenta de aproximação entre ficção matemática e realidade? Nesta discussão, busca-se entender alguns conceitos vinculados à teoria de Stengers, bem como discute como suas influências nas ciências contribuem para entender as aproximações que se tornam necessárias.

\section{REFERENCIAL TEÓRICO}

\subsection{As concepções filosóficas de Isabelle Stengers}

Através de sua obra intitulada A invenção das ciências modernas (1995), Stengers analisa a ciência sob diferentes perspectivas. De um lado, lança um olhar crítico à ciência moderna, mostrando que ela recorre a uma autoridade e à política em suas lutas por poder, buscando reafirmar-se e garantir autonomia e visibilidade; de outro lado, destaca que a ciência moderna é uma construção "singular", pois sabe reinventar-se fazendo uso sistemático e criativo, por exemplo, da matemática computacional, das tecnologias de informação e comunicação.

No livro A invenção das ciências modernas (1995), a autora usa o termo "ficção" para falar do poder de argumentos racionais que submetem os fatos, o poder que produz uma aparente submissão "do mundo a definições elaboradas no abstrato", STENGERS (1995). Este abstrato é a essência das ciências, pois partindo-se das ideias ou abstrações é que se consegue materializar por postulados, fórmulas e esquemas o que se configurará como processo de investigação científica. "Aí se acha a ficção que o é inicialmente e adentra ao mundo real após a divulgação dos resultados de pesquisas", STENGERS (1995).

Stengers inicia sua análise filosófica criticando certas visões epistemológicas do início do século passado que buscavam demarcar a ciência de outros saberes e, dessa forma, reinterpreta conceitos como singularidade, acontecimentos, explicação e nos remete à noção de produção de novos espaços, novos acontecimentos e novas explicações, não imutáveis e não universais, como afirma Stengers:

Um rumor inquietante se espalha pelo mundo dos cientistas. Existem, ao que parece, pesquisadores, ainda por cima especialistas em ciências humanas, que investem contra o ideal de uma ciência pura. [...] Os pesquisadores agrupados nesse campo ousariam pretender estudar a ciência à maneira de um projeto social como outro qualquer, nem mais descolado das preocupações do mundo, nem mais universal ou racional do que 
qualquer outro. Eles não mais denunciariam as numerosas infidelidades que os cientistas cometem contra as normas de autonomia e objetividade, mas as considerariam vazias, como se toda ciência fosse "impura" por natureza e não por estar distante do ideal. (STENGERS, 2002; p. 11)

Existem, aponta Stengers, do ponto de vista sociológico, aspectos "externos" à ciência que colocam o cientista não como produto de uma época e de uma história social, técnica, econômica e política, mas como agente ativo que tira partido dos recursos desse ambiente para fazer prevalecer suas teses e "esconder" suas estratégias sob a máscara da objetividade, como afirma Stengers:

\begin{abstract}
As questões da história "externa" das ciências ressurgem aqui, mas elas se tornam bem mais temíveis. Não se trata mais de uma tese geral sobre a solidariedade entre as práticas cientificas e seu ambiente. O cientista não é mais o produto de uma história social, técnica, econômica, política como qualquer ser humano. Ele tira partido ativo dos recursos desse ambiente para fazer prevalecer suas teses e ele esconde suas estratégias sob a máscara da objetividade. (STENGERS, 2002; p. 18)
\end{abstract}

As ciências não podem ser reduzidas a um simples exercício de poder. Tampouco estiveram livres de sua história. A política é parte intrínseca da atividade científica, o que não a torna necessariamente menos pura ou passível de ser denunciada. Na ousadia de fazer a associação entre razão científica e razão política, Stengers aponta a vulnerabilidade das ciências e a necessidade da íntima ligação com a historicidade humana. "Em nome da ciência", "em nome da objetividade científica", vemos serem criadas definições e redefinições de problemas que implicam a história humana". (STENGERS, 1995; p. 26). Busca-se, assim, articular aquilo que ela entende por ciência e o que entende por política, consciente de que podem ocorrer malentendidos e inquietações. Sua postura é de que nem a política explica a ciência, como um projeto cuja aposta é o poder, nem a ciência transcende à política. Nenhuma pode ter a pretensão e o poder de explicar a outra.

\title{
2.2 Contribuições de Stengers para as ciências.
}

Para Isabelle Stengers, as ciências modernas são constituídas de certas "singularidades" por sua capacidade de inventar novos meios e de suas produções e criações em laboratórios pelas práticas de caráter teórico-experimental. Essa dinâmica teórico-experimental difere a ciências da simples opinião. Stengers defende que a singularidade das ciências modernas implica na distinção entre sujeito e objeto, porque é desta distinção que surge o risco como um 
desalinhamento, que sugere o fato de a ciência moderna não parar de ser reinventada, não parar de inventar.

Na perspectiva em que a experimentação afirma-se como pratica singular, que não pressupõe mas cria tanto o sujeito e o objeto quanto suas relações, nenhuma versão dessas relações, por exata que seja, pode mais aspirar a uma validade geral. Paralelamente, a questão de saber o que acontece com a distinção entre sujeito e objeto em políticas cientificas que não seriam orientadas pela experimentação já não é uma questão filosófica, e sim uma questão imanente as ciências, ou seja, uma questão pratica. (STENGERS, 1995; p. 161)

Na visão de Stengers, nas ciências modernas o surgimento e o uso de modelos é capaz de colocar em questão a distinção entre a teoria e o modelo vinculado a escolha do autor. Nesse sentido esses modelos são espontaneamente ficções e ao mesmo tempo constituem uma forma de colocar à prova sem ter por objetivo eliminar os rivais. "Os modelos dizem espontaneamente que são ficções, a serem tratadas como tais. Contudo, constituem também uma maneira de se colocar à prova as ficções que não têm por alvo a eliminação dos rivais, e sim, o controle e a explicitação das consequências". (STENGERS, 1995; p. 163)

A ficção ganha espaço desde a época de Galileu, quando seu uso regrado descobriu na matemática um instrumento privilegiado. Nos dias de hoje, o uso da matemática como instrumento de ficção assume um novo porvir através do desenvolvimento das técnicas de informática e o uso de softwares. O computador como instrumento de simulação e criações de gráficos, por exemplo, coloca aos cientistas num novo compromisso, não mais de uma verdade que faz calar as outras ficções, mas de ter a possibilidade de construir a ficção matemática que o reproduz.

\begin{abstract}
As simulações em computador não propõem apenas o advento do uso ficcional da matemática, elas subvertem igualmente a hierarquia entre o fenômeno depurado, correlato da inteligibilidade ideal inventada pela representação experimental, e as complicações anedóticas. [...] Além do mais, a definição de "caso" só guarda da representação matemática a coerção de uma definição precisa, formalizável, das relações, e não obrigatoriamente a de uma definição das variáveis que correspondam a possibilidade de se colocá-la sob controle experimental. A arte do simulador e a do roteirista: colocar em cena uma multiplicidade heterogênea de elementos, definir de um modo que é o do "se... então..." temporal, narrativo, a maneira como esses elementos atuam juntos, depois acompanhar as histórias que essa matriz narrativa é capaz de originar. São essas histórias que põem a matriz a prova, e fazem da simulação uma experimentação sobre nossos enunciados. (STENGERS, 2002; p. 164 - 165).
\end{abstract}

Quando Galileu faz uso do "plano inclinado" (em o Discurso), para representar três tipos de movimento, ele usa uma mesa num plano inclinado para mostrar o movimento de queda, que é representado pela altura da queda, movimento horizontal sobre a mesa e o movimento de 
queda livre, que é representado pela distância que a bola consegue percorrer. Esse esquema representa um experimento que permite conceituar cálculos relativos à velocidade e movimentos uniformes. Para Stengers, esse artefato de laboratório, criado por Galileu em 1608, faz existir em laboratório o mundo que Galileu abre aos seus leitores em termos de experiência de pensamento. "É no curso da terceira jornada do Discurso a respeito das duas ciências novas que Galileu, sob o disfarce de Salviati, seu porta-voz, enuncia a definição do movimento uniformemente acelerado do qual gostaria de entender como e por que "tornou-se um acontecimento": [...]. (STENGERS, 1995; p. 93). Nesse acontecimento é bem nítido o conceito de movimento uniformemente acelerado, afirma Stengers.

Esse mundo matematizado proposto por Galileu, apesar de ser abstrato, é uma abstração que permite a criação de algo concreto. Trata-se, antes, de uma invenção de uma prática experimental que, além de distingui-la de outras ficções, cria um fato que singulariza uma classe de fenômenos entre outros. É nesse sentido que para Stengers a "representação" científica tem um sentido mais próximo da política, do que aquele que ela assume na teoria do conhecimento.

\footnotetext{
Quando falamos de "representação científica abstrata", referimo-nos com excessiva frequência a uma noção geral da abstração, comum, por exemplo, a física e as matemáticas. Ora, a abstração traduz aqui não um procedimento geral, mas um acontecimento: o triunfo local, condicional e seletivo sobre o ceticismo. [...] A abstração não é o produto de uma "maneira abstrata de ver as coisas". Ela nada tem de psicológico ou de metodológico. Ela diz respeito a invenção de uma pratica experimental que a distingue de uma ficção entre outras, ao mesmo tempo em que "cria" um fato que singulariza uma classe de fenômenos entre outros. (STENGERS, 2002; p. 106 - 107).
}

Para ela, as ciências modernas caracterizam-se pela "invenção de uma prática original" de atribuição de qualidade de autor que tira dois tipos de vantagem: o autor como indivíduo dotado de intenções, de projetos, de ambições e o autor que encarna autoridade. Esse é o sentido do acontecimento concebido pela invenção experimental: a invenção do poder de conferir às coisas, o poder de conferir ao experimentador o poder de falar em seu nome (STENGERS, 1995; p. 108).

\section{METODOLOGIA}

A metodologia deste artigo consistiu na utilização da pesquisa bibliográfica que para Cervo, Bervian e Da Silva (2007, p. 60) é aquela que "procura explicar um problema a partir de referências teóricas publicadas em artigos, livros, dissertações e teses" com o intuito de 
conhecer e analisar as contribuições culturais ou científicas do passado e da atualidade sobre determinado assunto, tema ou problema.

[...] a principal vantagem da pesquisa bibliográfica reside no fato de permitir ao investigador a cobertura de uma gama de fenômenos muito mais amplos do que aquela que poderia pesquisar diretamente. (GIL 2008, p.30)

Nesse sentido, buscamos fazer uma seleção de autores, livros, dissertações, teses entre outros, que enfatizassem a realidade no ensino da matemática buscando compreender o quadro atual e as aproximações que precisam ser feitas no Ensino da Matemática com a realidade usando softwares. Autores esses que trazem uma discussão do cenário no ensino da matemática de algumas décadas até os mais recentes dados coletados por pesquisas de órgãos como SAEB, INEP, entre outros, e sites críticos do ensino brasileiro na atualidade.

É de suma importância, ainda, deixar claro que esse artigo trata-se de um trabalho teórico buscando discutir dados oriundos de outras pesquisas na área com o objeto de pesquisa já experimentado. Nesse sentido esperamos fazer confronto do real com a teoria, pois segundo Severino (2002): “A ciência, enquanto conteúdo de conhecimentos, só se processa como resultado da articulação do lógico com o real, da teoria com a realidade”. (SEVERINO, 2002, p. 30).

Sztajn (2011, p.183), problematiza que "o objetivo principal da Educação Matemática no Brasil deve ser melhorar a atuação do professor no processo ensino-aprendizagem”. Logo, tendo determinado interesse pelo estudo, partiu-se da ideia de autores estudados e ainda de inquietações próprias, enquanto docentes formadores. Inquietações que estão além da sala de aula, passando por questões epistemológicas, sociais e culturais.

\section{RESULTADOS E DISCUSSÕES}

\subsection{Aproximação entre a ficção matemática e a realidade no Ensino de Matemática.}

O termo "ficção matemática", baseia-se no sentido de fazer ciências apenas no campo teórico sem sentido no campo experimental. "Nesse sentido, a ligação entre representação matemática e representação experimental - que nesse artigo chamaremos real - é um mistério pouco profundo" (STENGERS, 1995; p. 163). Em contrapartida, o uso dos "computadores" aproxima a realidade da ciência - nesse artigo trataremos mais a fundo do ensino da Matemática 
- com a "ficção matemática" e não apenas para o "mundo" de fórmulas e resolução de questões descontextualizadas, que não levam o aluno à realidade.

Nos dias de hoje, o uso da matemática como instrumento de ficção assume um novo porvir através do desenvolvimento das técnicas de informática. A força do computador como instrumento de simulação coloca aos cientistas um novo compromisso, não mais ao de uma verdade que exclui outras ficções, mas de - qualquer que seja o fenômeno - ter a possibilidade de construir a ficção matemática que o reproduz. Como afirmam os Parâmetros Curriculares Nacionais (BRASIL, 1998) que já enfatizam a importância dos recursos tecnológicos para a educação, visando à melhoria da qualidade do ensino e aprendizagem. Afirmam que a informática na educação "permite criar ambientes de aprendizagem que fazem sugerir novas formas de pensar e aprender" (BRASIL, 1998; p. 147).

$\mathrm{O}$ processo de aproximação entre a ficção matemática e a realidade no ensino de matemática, decorre de um processo histórico, pois durante um longo período na história, o conhecimento era oferecido de modo informal, pela família, tribo ou comunidade, sendo voltado ao aprendizado das observações das tarefas diárias, quando as crianças aprendiam conforme os costumes de suas origens. À medida que o tempo passou, veio a necessidade de adaptar-se a um mundo em transição, a evolução dos povos era inevitável e a vida se tornava mais complicada. Segundo Vitti (1999):

\footnotetext{
A história dos números tem alguns milhares de anos. É impossível saber exatamente como tudo começou. Mas uma coisa é certa; os homens não inventaram primeiro os números para depois aprenderem a contar. Pelo contrário, os números foram se formando lentamente, pela prática diária das contagens. (VITTI 1999, p. 50)
}

Segundo Boyer (2016, p. 14), os conhecimentos revelados nos papiros eram quase todos práticos e o elemento principal nas questões eram cálculos. Dando prioridade aos elementos teóricos para resolução de problemas não ligados à realidade dos alunos, que não os compreendem, afastando assim, a realidade e surgiram as dificuldades em matemática, levando muitos ao desinteresse pela disciplina. Na prática pedagógica deparamo-nos com alunos que apresentam dúvidas e resistência em desenvolver alguns conceitos matemáticos e uma grande oposição em aprendê-la. De fato, alguns revelam no cotidiano o sentimento que têm pela matemática.

A Matemática, para aqueles que vão ser matemáticos, ou seja, que têm o raciocínio lógico bem desenvolvido, é relativamente fácil, pois basta ao professor demonstrar as grandes linhas gerais e ensiná-los a aprender, deixando que eles busquem o que é de seu interesse, pois 
têm toda a vida pela frente para desenvolver o seu aprendizado. O problema é trazer a uma realidade os conteúdos matemáticos para aqueles que não têm interesse em aprender Matemática, os chamados de não matemáticos ou ainda, alunos desinteressados que só a aceitam como uma necessidade que ajuda a desempenhar suas atividades e adquirir nota para a sua aprovação e avanço de série ou ano. É muito importante pensar na Matemática de maneira universal, para que supostamente todos os cidadãos adquiram os conhecimentos necessários para a vida, a realidade ao sair da escola tratada nesse trabalho por Stengers. Parra (1996), afirma:

É preciso decidir a respeito dos conteúdos e também sobre a metodologia mais conveniente, para suprir em compensação muitos temas costumeiros que tem continuado a fazer parte dos programas, mas que hoje são inúteis. (PARRA,1996, p. 16)

Portanto, acreditamos que é preciso, desde as séries iniciais, educar levando em conta o raciocínio lógico e dedutivo do aluno a fim de que os conhecimentos sejam assimilados como parte natural da linguagem e do pensar cotidiano como algo importante para o desenvolvimento intelectual. Com isso, o educador deve estimular a criatividade, mostrando que a Matemática é um campo que está em constante movimento, como um edifício em construção, e necessita de modificações e adaptações.

Conforme esta visão de Stengers, o ensino de matemática precisa urgente de uma nova realidade que busque aproximar os conceitos aprendidos em ciências com o cotidiano dos alunos, a resolução apenas dos "quebra-cabeças" não leva a um avanço cientifico, pois para BRASIL (1998), o problema certamente não é um exercício em que o aluno aplica, de forma quase mecânica, uma fórmula ou processo operatório. Só há problemas se o aluno for levado a interpretar o enunciado da questão que lhe é proposta e a estruturar a situação que lhe é apresentada. (BRASIL, 1998, pág. 41).

Nesse sentido, as simulações computacionais não apenas propõem o uso ficcional da matemática, mas subvertem igualmente a hierarquia entre o fenômeno depurado, correlato da inteligibilidade ideal inventada pela representação experimental, e as complicações anedóticas, (STENGERS, 1995, p.165). Em outras palavras, a simulação computacional coloca em contato, sob um novo modo, o experimental, as leis, a descrição, a explicação, a ficção. Este é mais um elemento que as ciências modernas sabem aproveitar para se reinventar.

$\mathrm{Na}$ constante busca por contribuições pedagógicas que promovam aproximações com o real, Filho, Timóteo e Reis, em seu artigo intitulado: "contribuições do software GeoGebra no 
processo de ensino e aprendizagem de geometria analítica em uma turma da $3^{\circ}$ série do ensino médio", afirmam que o uso de softwares como o GeoGebra tem contribuições que vão além de métodos tradicionais de ensino:

Nesse contexto, entendemos que a utilização de recursos tecnológicos como internet e softwares educacionais, trabalhados de forma esquematizada, bem orientada, é capaz de abrir um leque de possibilidades didáticas, modificando inclusive as relações entre professor e aluno. (FILHO, TIMOTEO, COSTA E REIS, 2019, p. 292)

Na vivência escolar deparamo-nos com professores relatando que "a matemática precisa tornar-se fácil", dando a entender que ela é difícil ou na perspectiva de Stengers, apenas uma ficção matemática. Estes identificam na voz do aluno como uma disciplina chata e misteriosa que assusta e causa pavor. Assim, por consequência, o educando sente vergonha por não aprendê-la. Considerando tal realidade pela nossa experiência de alguns momentos em sala de aula. Quando nossos alunos não sabem comparar números racionais, por exemplo, se 1/3 é maior ou menor que $1 / 4$.

Umas das razões dessas dificuldades é que números racionais envolvem várias ideias e todas elas devem ser bem trabalhadas na sala de aula. Alguns alunos adquirem noções incompletas dos conceitos, vaga ideia do algoritmo, podendo aprender como somar ou dividir frações, mas de forma mecânica, sem verdadeira compreensão do que estão fazendo. Por isso, acabam, não sabendo responder questões do tipo: Comprei dezoito goiabas e $\frac{2}{3}$ delas tinham bichos. Quantas goiabas estavam estragadas?

Muito embora não exista uma receita pronta e acabada que possamos seguir para enfrentarmos os desafios de ensinar Matemática, queremos dizer que, antes de optar por um material ou um jogo, devemos refletir sobre os nossos paradigmas; sobre o papel de cada um, sobre o tipo de aluno que queremos formar, sobre qual matemática acreditamos ser importante para esse aluno. Segundo os PCN (2008):

\footnotetext{
É consensual a ideia de que não existe um caminho que possa ser identificado como único e melhor para o ensino de qualquer disciplina, em particular da matemática. No entanto, conhecer diversas possibilidades de trabalho em sala de aula é fundamental para que o professor construa a sua pratica. Dentre elas, destaca se a história da matemática, as tecnologias da comunicação e os jogos como recursos que podem fornecer os contextos dos problemas, como também os instrumentos para construção das estratégias de resolução. (PCN 2008, p. 42)
}

Ensinar Matemática é desenvolver o raciocínio lógico, estimular o pensamento autônomo, a criatividade e a capacidade de resolver problemas dos alunos. Nós, enquanto 
educadores matemáticos, devemos procurar alternativas para aumentar a motivação para a aprendizagem significativa, desenvolver a autoconfiança, a organização, concentração, atenção, raciocínio lógico-dedutivo e o senso cooperativo, desenvolvendo a socialização e aumentando as interações do indivíduo com o mundo real e a libertação apenas da ficção matemática.

\subsection{O uso do software GeoGebra como ferramenta de aproximação entre a realidade}

\section{e a "ficção matemática"}

Uma das alternativas de ajudar o aluno na obtenção da aprendizagem significativa em uma aproximação da ficção com o real, é utilizar softwares matemáticos - que Stengers chama de uso do computador - em sala de aula como o GeoGebra (disponível em www.geogebra.org) para mostrar possibilidades metodológicas no conteúdo de matemática. No site citado, podemos perceber que o software possui materiais didáticos prontos que possibilitam aproximação com a realidade nas áreas de probabilidade, estatística, álgebra, aritmética, funções, trigonometria, cálculos e outras.

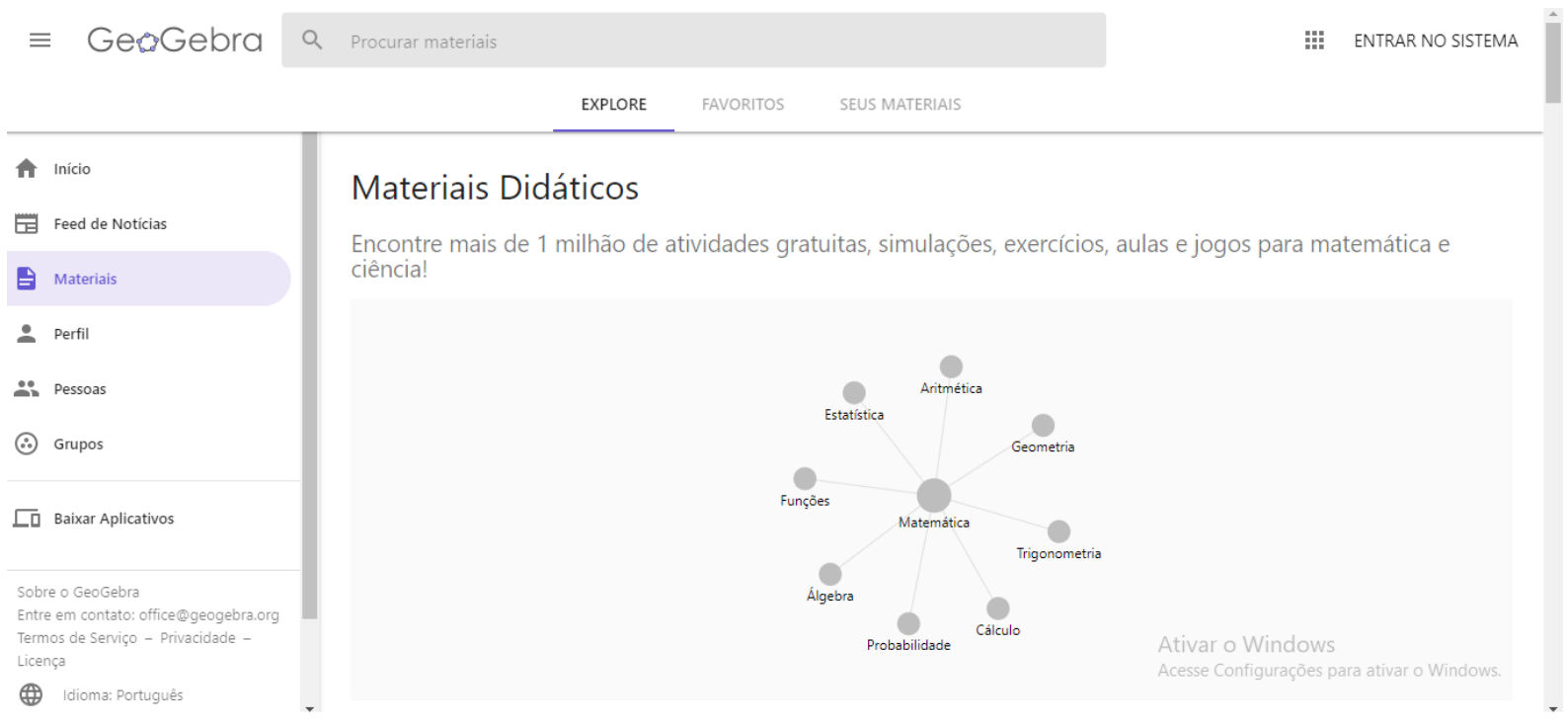

Figura 1: site GeoGebra

Fonte: www.geogebra.org

O Geogebra é um software de matemática dinâmico que permite construir e explorar objetos geométricos e algébricos e, ainda, construir gráficos de funções e muito mais de maneira interativa e atrativa, aproximando a teoria com o teórico-experimental. Foi desenvolvido pelo austríaco Markus Hohenwarter, da Universidade de Salzburg, em 2001, e destina-se para o 
ensino de Geometria, Álgebra e Cálculo nas escolas de Ensino Médio. De acordo com Hohenwarter, Jarvis, Lavicza, (2008, p. 84):

O Geogebra é um software dinâmico gratuito de código aberto, que oferece recursos de geometria e álgebra em um único ambiente, isto é, ele foi projetado para combinar recursos de software de geometria dinâmica e sistemas de álgebra computacional em um sistema único, integrado e fácil de usar para ensinar e aprender matemática.

Com o apoio do software GeoGebra, a aprendizagem pode ser bem mais significativa e real quando este, por exemplo, ao analisarmos os parâmetros a, b e c da equação do segundo grau na forma $y=a^{2}+b x+c$, fica fácil e prático de verificar o que cada parâmetro modifica na construção do gráfico da parábola com relação à concavidade da parábola, mudança de posição no eixo das abscissas e ordenadas de um plano cartesiano. No quadro-negro, o máximo que o professor pode fazer é desenhar parábolas quaisquer e diferenciar as mudanças que cada parâmetro opera. Não estamos cogitando a ideia de descartar os cálculos matemáticos construídos ao longo da história da matemática, mas sim trazer uma aproximação com a realidade de forma dinâmica e prática. Galileu fez uso de aproximações com a realidade, tais como essa no seu livro o Discurso, já citado neste artigo. (STENGERS, 1995; p. 93).

[...] os recursos de ensino são recursos humanos e materiais que o professor utiliza para auxiliar e facilitar a aprendizagem. São também chamados de recursos didáticos, meios auxiliares, meios didáticos, materiais didáticos, recursos audiovisuais, multimeios ou material institucional. (FERREIRA, 2007, p.25)

Esse exemplo da construção da parábola dados os parâmetros exposto acima, pode ser representado na imagem a seguir, que é uma construção usando os materias disponíveis no site www.geogebra.org, onde o aluno pode variar o parâmetro a, b ou c, percebendo as mudanças na posição da parábola e ainda a variação no discriminante, vértice da parábola e os zeros da função. Esse material pode facilmente ser acessado por um celular smartfone, computador, tablete e outra plataforma digital com acesso à internet. A vocação dos adolescentes para a utilização de recursos digitais é, também, um elemento facilitador, pois torna agradável o uso dessa ferramenta apresenta um inegável caráter significativo para a aprendizagem, conforme afirma Ferreira (2007). 


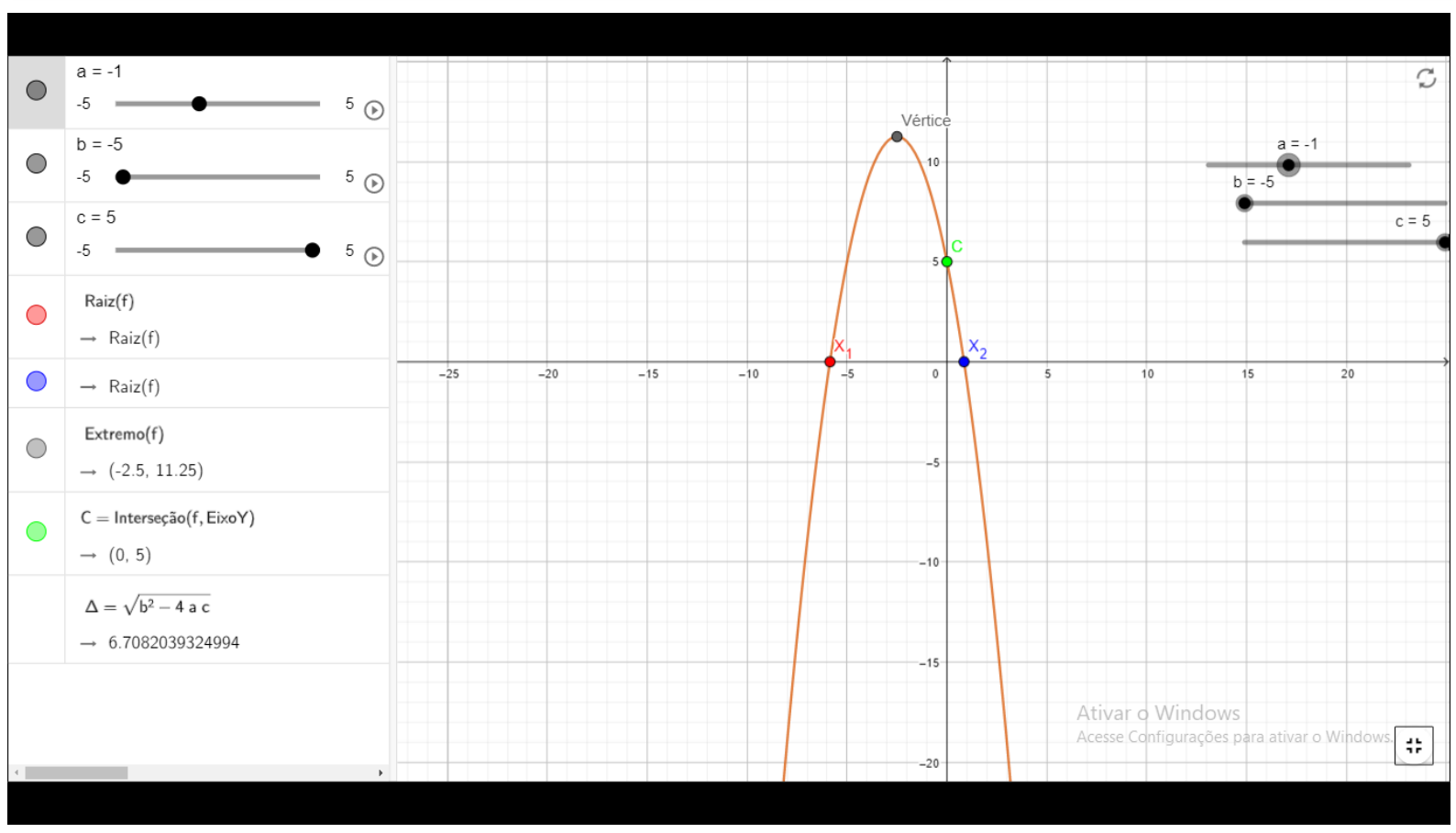

Figura 2: Função Quadrática - Raízes, Vértice e Discriminantes

Fonte: https://www.geogebra.org/m/sjr8x8qs, autor: Nilton Carlos Costa

Vale ressaltar que existem muitos outros materias e possibilidades didáticas dentro da plataforma do site, que aproximam o aluno com a realidade tratada nesse artigo. D’Ambrosio (1986), chama atenção para o fato de que em muitas situações o aluno se mostra mais confortável com o uso de tecnologias, como o uso do computador e softwares do que o próprio professor, visto que nos últimos tempos as crianças e jovens fazem uso dessa tecnologia em jogos e brincadeiras que são disponibilizados aos mesmos por meio da tecnologia. O uso de softwares como o GeoGebra permite mostrar aos alunos com clareza a construção de diversos tipos gráficos de funções de maneira rápida e sem causar enfado no aluno e no professor, funcionando como a ligação daquilo que o aluno já sabe com a nova ideia a ser aprendida. Gomez (1997), afirma:

[...] mesmo que o uso das tecnologias não seja a solução para os problemas de ensino e de aprendizagem da Matemática, há indícios de que ela se converterá lentamente em um agente catalisador do processo de mudança na educação matemática. Graças às possibilidades que oferece para manejar dinamicamente os objetos matemáticos em múltiplos sistemas de representação dentro de esquemas interativos, a tecnologia abre espaço para que os estudantes possam viver novas experiências matemáticas (difíceis de conseguir com recursos tradicionais como o lápis e o papel), visto que pode manipular diretamente os objetos matemáticos dentro de um ambiente de exploração. (GOMEZ, 1997, p. 27)

Diante da afirmação de Gomez (1997), o uso de software como o GeoGebra, estimula o raciocínio-lógico e aproxima com a realidade que tanto se está enfatizando, seja despertado 
em nossos alunos para aprender com significado. O uso do software GeoGebra, além de produzir um estímulo significativo na aprendizagem, promove interações em outras áreas, mostrando as possibilidades que o ensino da matemática traz em sua aplicabilidade, bem como no seu processo de formação em conceitos, fórmulas e cálculos, como afirma:

\footnotetext{
Por fim, acreditamos que a aprendizagem de Geometria favorece três diferentes formas de processos cognitivos com funções epistemológicas específicas: a visualização, a construção de figuras e o raciocínio. Neste contexto, esperamos com essa investigação, contribuir para reflexões e discussões a respeito do ensino de Geometria Analítica, bem como sobre o processo de ensino e aprendizagem com a utilização do software Geogebra. (FILHO, TIMOTEO, COSTA E REIS, 2019, p. 310)
}

Não diríamos que isso irá resolver o problema que por muito tempo se encontra tão presente em nosso meio, mas é uma opção de um leque que já existe e gostaríamos de reforçar sua importância no meio educacional, que principalmente no ensino de matemática é tão malentendido e vítima de preconceitos que precisam, tão somente, ser quebrados. O uso computacional faz-nos lembrar dos paradigmas de Kuhn (1969), que precisam ser rompidos no ensino da matemática e softwares como o GeoGebra, trazem consigo uma forma diferente e abrangente em recursos e ferramentas a serem explorados, promovendo uma ligação entre o ficcional e o real.

\section{CONSIDERAÇÕES FINAIS}

Os desafios com que os professores se deparam cotidianamente, o mundo virtual (alunos com acesso a wikis, blogs, redes sociais, textos provisórios, comentáveis, editáveis, de validade, às vezes, "relativa") favorecem uma perspectiva de "discutir o conhecimento". Entretanto, o mundo virtual mostra faces, no mínimo, ambíguas: de um lado, favorece a democratização do conhecimento. De outro, compromete a qualidade das informações, distorce-as, por vezes.

Sendo assim, uma atitude de simplicidade e aceitação de que se pode recorrer aos meios tecnológicos, constitui-se como uma possibilidade que extrapola os limites da utilidade e afirma-se como elemento motivador não somente para novas descobertas, mas também para que as práticas antigas ganhem uma nova significação. Por vezes, o que aparenta ser obsoleto, não o é de fato. Estava apenas em desuso, mas continua a ser extremamente útil. Nesse particular é que o Geogebra aparece para confirmar nossas suposições que ora saem da condição de simples DOXA e ganham caráter de EPISTEME. 
O que não se pode é ignorar que vivemos em um período de mudanças sociais profundas.

Muitas resultam da revolução tecnológica, proporcionada pela ciência. Essas mudanças interferem tanto nos modos como recebemos e lidamos com a informação, quanto nas escolhas, nas opções de consumo, nas formas de relacionamento e por que não dizer na forma como concebemos a ciência e como ensiná-la. Refletir sobre tais questões é, portanto, mais do que pertinente.

\section{REFERÊNCIAS}

ALMEIDA, D.P. Aprendizagem significativa em espaços educativos: o uso dos quelônios como tema facilitador. 2016. Dissertação (Mestrado em Educação em Ciências na Amazônia), Universidade do Estado do Amazonas, Manaus, 2013.

BOYER. C.B. História da Matemática. São Paulo, Ed. Edgard Blücher, 2014, Reimp. 2016. 496p.

BRASIL. Parâmetros Curriculares Nacionais: Matemática/ Secretaria de Educação Fundamental. - Brasília: MEC/SEF, 1998.

D’AMBROSIO, Ubiratan, Da Realidade à ação: Reflexões sobre Matemática. São Paulo, Summus Editorial. 1986.

EDUCADOR BRASIL ESCOLA. A história do ensino de matemática na sala de aula. Estratégias de Ensino. Disponível em: <(https://educador.brasilescola.uol.com.br/estrategiasensino/a-historia-ensino-matematica-na-sala-aula.htm>, Acessado em 02 de Fevereiro de 2020.

FELICETTI, S. A.; PASTORIZA, B. S. Uma experiência visando a aprendizagem significativa, a partir do conceito de geração e aproveitamento de energia elétrica. Revista Góndola, Enseñanza y Aprendizaje de las Ciencias. Bogotá, Colombia, 2015 http://revistas.udistrital.edu.co/ojs/index.php/GDLA/index >http://www.filoinfo.net/node/54, acesso às 08:32:21 do dia 23/09/2018.

FERREIRA, S. M. M. Os recursos didáticos no processo de ensino-aprendizagem. 68 p. Dissertação (Monografia) - Universidade Jean Piaget de Cabo Verde. 2007.

FILHO, A.; TIMÓTEO, S.; COSTA, D.; REIS, S. Contribuições do software GeoGebra no processo de ensino e aprendizagem de geometria analítica em uma turma da $3^{\circ}$ série do ensino médio. Revista REAMEC, Cuiabá - MT, v. 7, n. 1, jan/jun 2019, p. 288 - 311. Disponível em : <http://periodicoscientificos.ufmt.br/ojs/index.php/reamec > Acessado em: 27 de fevereiro de 2020.

GÓMEZ, P. Tecnología y educación Matemática. Rev. Informática Educativa. uniandes lidie. Vol 10, No. 1. Pp 93-11, 1997.

HOHENWARTER, Markus; JARVIS, Daniel; LAVICZA, Zsolt. Linking Geometry, Algebra, and Mathematics Teachers: Geogebra Software and the Establishment of the 
International Geogebra Institute. International Journal for Technology in Mathematics Education. [online]. v.16, n. 2, p. 83-87, jul. 2008. Disponível em: < https://www.researchgate.net/publication/307936818_Linking_Geometry_Algebra_and _Mathematics_Teachers_Geogebra_Software_and_the_Establishment_of_the_Internati onal_Geogebra_Institute>. Acesso em: 27 de fevereiro de 2020.

PARRA, C. SAIZ: Matemática/ Secretaria de Educação Fundamental, I. Didática da Matemática: Reflexões Psicopedagógica. Porto Alegre, Artmed (Artes Médicas). 1996. 258p.

PCN - Parâmetros Curriculares Nacionais - Brasília: MEC/ SEF. 2008. 148p.

PRIGOGINE, I.; STENGERS, I. A nova aliança: metamorfose da ciência. Brasília: Univ. de Brasília, 247 p., 1991.

SANTOS, S. C. S.; FACHÍN-TERÁN, A. Aprendizagem significativa, modelos mentais e analogias no contexto construtivista: uma aproximação possível para a educação em Ciências. In: BARBOSA, Ierecê et. al (org.). Educação em Ciências na Amazônia: múltiplos olhares. Manaus: UEA/Escola Normal Superior/PPGEECA, 2011.

SEVERINO, A. J. Metodologia do trabalho científico. 22a edição, São Paulo: Cortez, 2002.

STENGERS, Isabelle. A invenção das ciências modernas. Tradução Max Altman. São Paulo: Ed. 34, 2002.

STENGERS, I. L'invention des sciences modernes. Paris: Champs-Flammarion, 1995.

VITTI, C. M. Matemática com prazer, a partir da história e da geometria. $2^{\mathrm{a}}$ Ed. Piracicaba - São Paulo. Editora UNIMEP. 1999. 103p.

Submetido em: 28 de outubro de 2019.

Aprovado em: 25 de fevereiro de 2020. 